\title{
SPOOLS: SUSTAINABLE POOLS - MAIN DEVELOPMENTS OF THE PROJECT
}

\author{
MIGUEL JOSÉ OLIVEIRA ${ }^{1 *}$, ALFREDO BRAGA $^{1 \dagger}$, ARMANDO INVERNO $^{2}$, CARLOS SANTOS $^{2}$, \\ ELISA M. J. DA SILVA ${ }^{1 *}$, FRANCISCO DO CARMO ${ }^{3}$, LUÍS SILVA ${ }^{5}$, MANUELA MOREIRA DA SILVA $^{4 \S}$, \\ PAULO CABRAL ${ }^{1}$, PEDRO SEQUEIRA $^{5}$ \& RUI LANÇA ${ }^{1 * *}$ \\ ${ }^{1}$ Civil Engineering, Institute of Engineering, University of Algarve, Portugal \\ ${ }^{2}$ Mechanical Engineering, Institute of Engineering, University of Algarve, Portugal \\ ${ }^{3}$ Cristal Construções - Materiais e Obras de Construção Civil, Portugal \\ ${ }^{4}$ CIMA, Institute of Engineering, University of Algarve, Portugal \\ ${ }^{5}$ Weber Saint-Gobain, Portugal
}

\begin{abstract}
The University of Algarve in consortium with Saint-Gobain Weber Portugal and Cristal Construções Materiais e Obras de Construção Civil is developing a new concept of sustainable swimming pool which is more energy efficient with less environmental footprint and with reduced construction and maintenance costs. The specific objectives are the use of recycled materials, the reduction of the $\mathrm{CO}_{2}$ emissions in the life cycle of the construction materials, the reduction of the water losses, the use of renewable energy from the sun by exploiting the thermal inertia of the materials surrounding the swimming pool and the reduction the energy consumption during the structure lifetime by increasing the durability and reducing the number of reparations. To this end, new formulations of concrete and mortar are being developed and tested in our laboratories. They incorporate recycled materials and also materials with reduction of $\mathrm{CO}_{2}$ emissions during the production phase. An important concern is related with the development of an innovative system for the use of renewable energy from the area surrounding the swimming pool. One of the outputs of this project will be the construction of a semiscale prototype of a swimming pool with dimensions of $10 \mathrm{~m} \times 5 \mathrm{~m} \times 1.5 \mathrm{~m}$, and with the characteristics mentioned above, in order to observe and validate the proposed developments.

Keywords: sustainable swimming pool, swimming pool prototype, aggressive chemical environment, binder joint mortar, thermal inertia, solar energy PCM heat accumulator, dry-mix recycled aggregates shotcrete.
\end{abstract}

\section{INTRODUCTION}

The Algarve is a known touristic destination in Portugal, and one of the most popular in Europe. It receives millions of international and national tourists annually, and the population triples in the summer. It is a region geographically located in the south of Portugal, with an area of $4997 \mathrm{~km}^{2}$ and a permanent resident population of 451006 inhabitants [1]. The administrative centre is located in the city of Faro, as well as its international airport and public university, the University of Algarve. Tourism and related activities are extensive and make up the bulk of the Algarve's economy.

Since tourism is considered to be one of the major economic activity in the region, the seasonality is one of the most unfavourable aspect on the economy, and therefore new investments and markets are being studied, in order to allow a strong economy during the all year [2].

\footnotetext{
*ORCID: http://orcid.org/0000-0002-3042-0802

ORCID: http://orcid.org/0000-0002-8868-8879

HORCID: http://orcid.org/0000-0003-0037-2798

sORCID: http://orcid.org/0000-0002-3331-8280

** ORCID: http://orcid.org/0000-0002-7753-3767
} 
Worldwide, tourism is one of the global engines of development and every year the numbers shows that more people are travelling. With good planning and management, tourism can be a positive aspect, bringing benefits to destinations around the world, but on the other hand, if poorly planned and managed, tourism can be an engine for degradation. So, it is clearly in the interest of the touristic sector to maintain the activity sustainable [3]. The Algarve authorities are aware of this reality and, among other measures, are working together with the University of Algarve to implement an observatory of the region's sustainability [4].

Algarve is known by its amazing golf courses and a warm and sunny climate and the tourists appreciate the houses and hotels with swimming pools, preferably surrounded by grass and threes that provide a pleasant landscape. So, tourism depends to a considerable degree on water, which is a resource needed to provide services related to basic human needs and for a wide range of tourism activities [5]. It is estimated that in the Algarve there are more than 30.000 swimming pools.

Tyler et al. [6] simulated the environmental impact on residential swimming pools in the Arizona (USA) and on other warmer regions. They refer that the water footprint range from 45 to $185 \mathrm{~m}^{3} /$ year/swimming pool, while the estimated energy footprint range between 2400 and $2800 \mathrm{kWh} /$ year/swimming pool. The carbon footprint of the modelled pools was estimated to be $1400 \pm 50 \mathrm{~kg} \mathrm{CO}$ e $/$ year/swimming pool.

The construction, installation and maintenance of swimming pools is relatively recent, existing on a large scale only in the last 50 years. During this period, the technologies evolved significantly. Nowadays there are different solutions for the construction of swimming pools. Most of the existing swimming pools in Portugal correspond to small swimming pools, built in residential areas and still characterized by little detail, or even nonexistence, of design covering up the absence of specific technical information, norms and technical experts. Most of the companies that operate on the pool market are small and medium-sized and follow the private segment, more stable and with more guaranteed demand (even if subject to the national conjuncture of the construction) in order to maintain the economic viability. In the last 20 years, the evolution of the supply (number of companies that are available to perform and/or install swimming pools) and the demand (public willingness to buy a certain type of pools versus the alternatives) in the construction has increased. In addition, there is the market segment of swimming pool rehabilitation, namely due to the dysfunctional nature of the waterproofing system, degradation of the materials and also for aesthetic reasons.

In particular, in the Algarve region, the execution and maintenance of swimming pools constitute an important business unit at economic level, not only for the direct contribution to more than 500 companies that work directly in the field, but also for the referred tourist need - hotel units and private houses.

A swimming pool design involves a set of agents and processes that justify central coordination. It usually involves the construction of concrete walls, regularization with specific plasters or mortar, the application of mortars or specific waterproofing systems, coating systems, paints, liners or others. After the construction, the constant presence of water, chemical cleaning agents, $\mathrm{pH}$ adjustments, biocides, among others, may affect the material's behaviour and the durability of the entire system.

The University of Algarve in consortium with Saint-Gobain Weber Portugal and Cristal Construções - Materiais e Obras de Construção Civil is developing a new project that will respond to the global demands and challenges, of a more sustainable and efficient swimming pool. The most relevant aspects to highlight are: 
1. Characterization of the chemical aggressiveness of treated or untreated swimming pools waters, in order to allow the development of materials and maintenance practices that can increase the durability of the constructed systems;

2. Mineral binder joint mortar with high resistance to aggressive chemical environment;

3. Use of the heat transmitted by the solar radiation to the surrounding pool floors in order to increase the swimming pool water temperature in the middle and cool seasons (spring, winter and autumn) and the pool use without heating systems that have high energy demand;

4. Incorporation of waste, namely recycled aggregates in the sprayed concrete applied in the swimming pool structure;

This project, with a duration of two years, will terminate in December 2018. Therefore, in this article, only the developments registered until now, will be presented. The final results, namely those resulting from the monitoring of the prototype of the pool, will be the object of further publications.

\section{WATER RESOURCES AND WATER FOR SWIMMING POOLS PURPOSES}

Coastal resorts became increasingly popular as tourist destinations [7] and Algarve is among them. During the last years several social and economic factors such as, low cost airlines, political instability and terrorism in other tourist destinations, are bringing to Algarve an escalating number of tourists looking for leisure activities, most of them related to water.

Natural resources in the Algarve region, particularly the water resources, are suffering high pressure from agriculture, industry and particularly from tourism investments [8]. Several dams were constructed to increase the water resources available in the region, namely Odeleite, Beliche, Odelouca, Funcho, Arade and Bravura. The dam's reservoir along with the groundwater abstractions, assure the water for domestic and agricultural uses, including the summer season, when the population is three times higher due the tourism. The sustainable water management is crucial, and the problems faced are often complex and multidisciplinary [9]. It is necessary to assure not only enough water in high demand periods, but also good water quality, protecting the public health and the environment. Attending to the vulnerability of the coastal zones, the choice of the water source for each use must comply with an integrated management strategy [10]. In this scenario, the sources of water are variable, according to the location and characteristics of the swimming pool.

From a chemical perspective, swimming pools are a complex matrix, with continual addition of a wide range of natural and anthropogenic chemicals via filling waters, disinfectant addition, pharmaceuticals and personal care products as well as human body excretions. Chlorine-based chemicals (e.g. hypochlorite) are the most used products for water pool disinfection, due to its low cost, keeping swimming pool water microbiologically safe and hygienic [11]-[13]. This results in extremely high chloride, acidic or strongly oxidizing agent (e.g. $\mathrm{Cl}_{2}, \mathrm{OCl}^{-}$) concentrations in the swimming pools water. Chlorine used for disinfection reacts with water and forms hypochlorous acid and hydrochloric acid. For effective disinfection, it is advisable to use water with lower $\mathrm{pH}$ values, which means a higher capacity to corrode the building materials used in the pool construction [14].

For this research project, 76 water samples were collected between March and November of 2017. The waters from different sources (surface water, groundwater or salt water), were characterized before and after the disinfection treatment. Temperature in situ and in laboratory was measured, as well as the following parameters: $\mathrm{pH}$, Residual Chlorine, Total Chlorine, Calcium, Magnesium, Conductivity at $20^{\circ} \mathrm{C}$, and Oxidability. The Lime Index (LiF) was calculated according to Felixberger Josef [15]. All analytical essays were performed by 
the Sanitary Engineering Laboratory of the University of the Algarve, accredited for water analysis, using standard methods according to Eaton et al. [16].

Based on the LiF, the obtained results showed that $76 \%$ of the studied pools should be constructed using cement in waterproofing, laying and grouting. About $20 \%$ of pools need epoxi materials in laying or in grouting, to prevent corrosion effects. Just $4 \%$ of the pools indicated need epoxi materials in waterproofing, laying and grouting, and these cases are related with the use of brackish water for swimming pools purposes.

\section{DEVELOPMENT OF MINERAL BINDER JOINT MORTAR}

As referred, swimming pools present high demands on materials, since the constant $\mathrm{pH}$ and temperature adjustments contributes to a more aggressive environment. In this context, considering that the finishing layer consists in a mosaic tile with a joint grout mortar between the tiles, both elements need considerable resistance to such environment. Experience shows that the joint grout mortar represents the weakest part of the finishing layer, especially when it is made with mortars based in mineral binder, such as Portland cement. As a result, it is common to apply other solutions, mainly based from epoxy binder; even so, it is a less environmentally sustainable material, more expensive, with high safety risks to applicators and degradation may also occur due to exposition to Ultraviolet (UV) radiation.

The present project intends to develop a joint grout mortar based on mineral binder with higher resistance to lower pH's as calcium alumina cement (CAC), although, it is well known that the typical phase conversion, leads to a loss of resistance in time [17]. In order to find a solution to this effect, and simultaneously to resist to aggressive chemical environment, a combination of different mineral binders is proposed. To identify potential threats and assure a good performance of this mortar in a swimming pool, cylindrical samples of the mortar with $25 \mathrm{~mm}$ of diameter and $25 \mathrm{~mm}$ of height, were tested according to the following procedures:

1. Compressive strength at normal conditions and after chemical exposure; as specification to the mentioned aggressive environment, is intended that compressive resistance should not:

a. Decrease more than $25 \%$ compared to standard curing conditions;

b. Decrease below 25MPa;

c. Compressive strength at normal curing conditions should be higher as possible (recommended $>25 \mathrm{MPa}$ );

2. Chemical exposure according EN 13808-1:2008, considering fresh water every day and $\mathrm{pH}$ updating:

a. 3 samples are stored in standard conditions $\left(\mathrm{Hr}: 55 \% ; \mathrm{T}: 22^{\circ} \mathrm{C}\right)$ for 35 days;

b. 3 samples are stored 7 days in standard conditions (Hr: $55 \%$; $: 22^{\circ} \mathrm{C}$ ), followed by 28 days in water immersion;

c. 3 samples are stored 7 days in standard conditions (Hr: $55 \%$; $: 22^{\circ} \mathrm{C}$ ), followed by 28 days in water with $\mathrm{pH}=3$ (prepared with $\mathrm{HCl}$ ) changing solution every day;

d. 3 samples are stored 7 days in standard conditions ( $\mathrm{Hr}: 55 \%$; $\mathrm{T}: 22^{\circ} \mathrm{C}$ ), followed by 28 days in water immersion, changing water every day;

e. Evaluation/registration of the apparent density, dimensional variation (EN 12808-4), compressive resistance (EN 12808-3) and surface degradation.

The tests results using the developed grout mortar and using a Portland cement-based mortar, are presented on Table 1. 


\section{CONCRETE POOL DECK HEAT ACCUMULATOR}

The major objective of the concrete pool deck, constructed on the surrounding of the swimming pool, is to capture the solar heat and use it for the water heating. This is an innovator concept, being even more challenging since will be used recycled aggregates combined with phase change materials (PCM).

\subsection{The use of recycled aggregates on the concrete}

The widespread use of natural aggregates in construction activities, together with the global population increase, gave rise to the depletion of this natural resource and to progressive increase of its transport distances. On the other hand, the construction and demolition wastes (C\&DW) resulting from the construction activities are often deposited in landfills and city outskirts, causing environmental and social impacts, such as erosion, deforestation, water contamination and human conflicts. The reuse of C\&DW in concrete preparation would be a good solution for both problems. Recycling of C\&DW is, however, a complex challenge due to the high heterogeneity associated to these materials. Recycled aggregates (RA), prepared of C\&DW, generally show lower quality properties than natural aggregates (NA) [18].

The RA used in this research project were provided by the recycling plant "MultiTriagem", which collects and manages the C\&DW from the Algarve southwest. Primary reduction of the rubble was made with a shear. Then a primary and secondary crushing was performed using a portable Impact Crusher, fitted with two hammers and a magnetic separator. Finally, the aggregates were sieved to obtain the desired fraction. Two types of coarse aggregates, labelled CeRA (Ceramic RA) (Fig. 1(a)) and CoRA (Concrete RA) (Fig. 1(b)), were used.

Table 1: $\quad$ Tests results using a mineral joint grout mortar and a Portland cement-based mortar, exposed to standard and aggressive conditions (case $\mathrm{pH}=3$ ).

\begin{tabular}{cccc}
\hline Test conditions & Parameters & Joint grout mortar & Portland based mortar \\
\hline \multirow{2}{*}{ Standard } & Apparent density & 2.17 & 1.83 \\
conditions & Compressive strength $(\mathrm{MPa})$ & 50.28 & 32.52 \\
& Dimensional variation $(\mathrm{mm} / \mathrm{m})$ & 0.346 & 0.644 \\
\hline Aggressive & Compressive strength $(\mathrm{MPa})$ & 54.42 & 23.63 \\
conditions & Dimensional variation $(\mathrm{mm} / \mathrm{m})$ & -1.41 & $-3,09$ \\
(case $\mathrm{pH}=3)$ & Surface degradation level & No degradation & High degradation \\
\hline
\end{tabular}

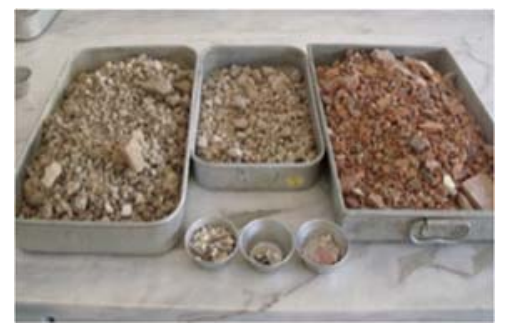

(a)

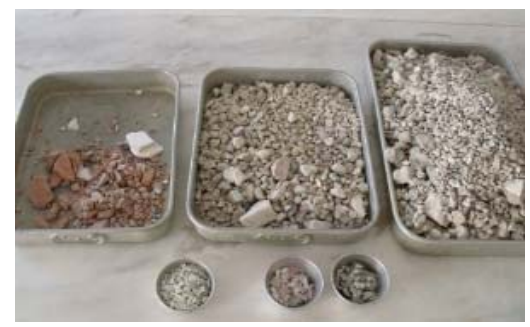

(b)

Figure 1: Recycled aggregates. (a) CeRA aggregates; (b) CoRA aggregates. 
The materials were obtained according to EN 933-11 (Table 2), where the abbreviation stands for: Rc-concrete, concrete products, masonry concrete blocks; Ru-unbounded aggregates, natural stone, treated aggregates with hydraulic binder; Rb-ceramic elements (e.g. bricks, roof tiles, etc), not floating cellular concrete and masonry blocks; Ra-bituminous materials; Rg-glass; X-cohesive materials (soil, clay, etc.), metals, wood, plastic, rubber, stucco; FL-floating materials. The specific dry density is respectively 2.06 for CeRA and 2.23 for CoRA (EN 1097-6).

For the optimization of the concrete the Faury method (reference curve) was applied, firstly for a reference concrete with normal aggregates and then with the total replacement of these by the recycled aggregates. Subsequently, identical concretes were prepared in different colours, by introducing pigments of dark blue (Fig. 2(a)) and green (Fig. 2(b)).

The idea was to observe its thermal behaviour when exposure to solar heat. Therefore, after demoulding, the samples were placed in the sun for daily recording of temperatures, both on the upper and lower faces.

\subsection{PCM heat accumulator for swimming pool heating}

Outdoor swimming pools are featured by high heat losses mainly due to free water surface convection and evaporation to the surrounding air and radiation to the sky. There are also other factors, although less important, like transmission to the soil vicinity, when the structure is buried, and water makeup due by evaporation and filters backwash.

In the Algarve region, the water temperature attends comfortable swimming and leisure activities only in summer, and even so, just if there is plenty of solar radiation, namely when the amount of direct solar radiation is enough. Solar radiation is the only free (unpaid) energy able to overcome the named losses. Other external energy systems can be used to provide the complement needed to keep the water temperature, but it implies financial costs and environmental impacts. Those active heating systems, namely electric heat pumps, gas boilers and not solar collectors, are quite frequent in Algarve, both in private swimming pools, villas and touristic resorts. In fact, actual swimming pools are still considered very low sustainable equipment's, since the energy comes from conventional non-renewable sources.

Table 2: Constitution of the CeRA and CoRA recycled aggregates.

\begin{tabular}{cccccccc}
\hline Aggregate & $\mathrm{Rc}(\%)$ & $\mathrm{Ru}(\%)$ & $\mathrm{Rb}(\%)$ & $\mathrm{Ra}(\%)$ & $\mathrm{Rg}(\%)$ & $\mathrm{X}(\%)$ & $\mathrm{FL}\left(\mathrm{cm}^{3} / \mathrm{kg}\right)$ \\
\hline CeRA & 49.18 & 8.88 & 41.70 & 0.02 & 0.28 & 0.34 & 0.43 \\
\hline CoRA & 71.44 & 24.18 & 3.86 & 0.22 & 0.40 & 0.25 & 0.20 \\
\hline
\end{tabular}

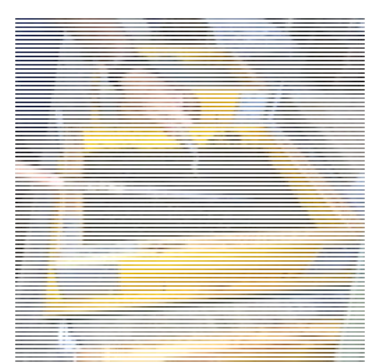

(a)

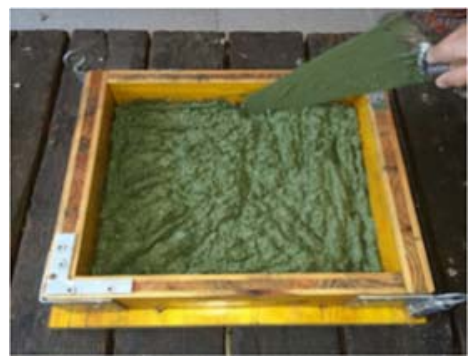

(b)

Figure 2: Preparing mortar samples. (a) Dark blue pigments; (b) Green pigments. 
A swimming pools owners' rational and responsible practice, concerning energy savings, consists of applying a water surface cover, which reduces radiation and convection losses. Only the use of such cover can reduce significantly those losses and consequently it allows an increment of the water temperature, all year around. A survey performed on a $50 \mathrm{~m}^{2}$ surface swimming pool locate in Faro city, Algarve, showed that the water temperature raises about $2^{\circ} \mathrm{C}$ between April to August, and a little bit less in the remaining time. Although these values seem, apparently, without a significant expression, they represent a great energy saving, as the mass of water is 85 tons.

Since, the main goal is to obtain higher water temperature mainly in periods which can surpass summer, and also decrease the difference between day and night, using only solar energy (sustainable solution), then the heating solution must take into account the two following postulates: i) the swimming pool as to be as efficient as the pool water "solar absorption-heat accumulator" (environmental aspect); ii) preferably not very expensive, in order to be economically viable to launch it on the market (economic aspect).

The solution proposed and discussed in the present paper considers the incorporation of a phase change material (PCM) in the slab concrete floor, around the swimming pool. Remember that water is a good solar receiver (its solar absorption coefficient ranges from $0,85$ to 0,90$)$, and the water volume in the pool makes it a great heat accumulator. Due to its high heat capacity, as a consequence of its high enthalpy of fusion, the PCM material was considered as a potential solution to work out as a heat accumulator. There are enormous types of PCM, as Zalba et al. [19] and Soares et al. [20] listed, some more suitable for using in swimming pools heating process with solar energy as the heat source, for temperatures ranging from $23^{\circ} \mathrm{C}$ to $26^{\circ} \mathrm{C}$, or even a little more. One of those PCM, the Micronal ${ }^{\circledR}$ DS 5040 $\mathrm{X}$, will be incorporated in the composition of mortars and then applied in the area around the swimming pool.

An experimental mortar with $25 \%$ in mass of $\mathrm{Rc}$ has proved to be unsuitable to the purposes, being unable to fulfil all the required functions (mechanical resistance and aesthetics), after cracking superficially.

Samples of these mortars were also thermally tested. Fig. 3 shows the temperature evolution of a $10 \mathrm{~cm}$ height and $900 \mathrm{~cm}^{2}$ surface sample of common dark Rc mortar, without PCM's. The sample was exposed to sun radiation, on a horizontal plane, for several days in the beginning of August of 2017. The measurements were taken daily, with a laps time interval of 30 minutes, continuously over successive days. The solar radiation and air temperature where also registered at the same time. The period in question was chosen, since it corresponds to the worst-case scenario: air and water temperatures are lower, as well as the solar radiation angle. Fig. 4 shows the results of the same test, performed on green coloured Rc mortar with PCM, in the beginning of October of 2017.

As showed in Fig. 3 and Fig. 4, the evolution of the global horizontal solar radiation is almost the same, despite the two-month difference and the 45 minute's sunrise delay. The temperature in both samples, follows the same trend line, for the $5 \mathrm{~mm}$ and $25 \mathrm{~mm}$ depth. Before sunrise, both samples show a uniform and almost constant temperature with depth, although the variation is smaller on the dark Rc mortar sample (without PCM), meaning that the thermal inertia of this mortar is low. After the sunrise, and with the increment of solar radiation and temperature exposure, both samples registered a significant increment of the temperature near the top of the samples, namely $\Delta \mathrm{T} \cong 15^{\circ} \mathrm{C}$ on the dark Rc mortar sample and only $\Delta \mathrm{T} \cong 10^{\circ} \mathrm{C}$ on the green Rc mortar sample, showing the influence of the colours in the capture of energy. The evolution of the temperature with time, at $25 \mathrm{~mm}$ depth, as a lower variation, as it was expected, although the dark colour sample stills presents the major increase, with $\Delta \mathrm{T} \cong 9^{\circ} \mathrm{C}$ against $\Delta \mathrm{T} \cong 3^{\circ} \mathrm{C}$ for the green mortar sample. In Fig. 4 , immediately 
after the sunrise, it is possible to observe that the temperature at $25 \mathrm{~mm}$ depth is a little bit higher $\left(\cong 2^{\circ} \mathrm{C}\right)$ than at $5 \mathrm{~mm}$ depth, showing the influence of PCM on the thermal behaviour of the mortar, which works as a heat accumulator.

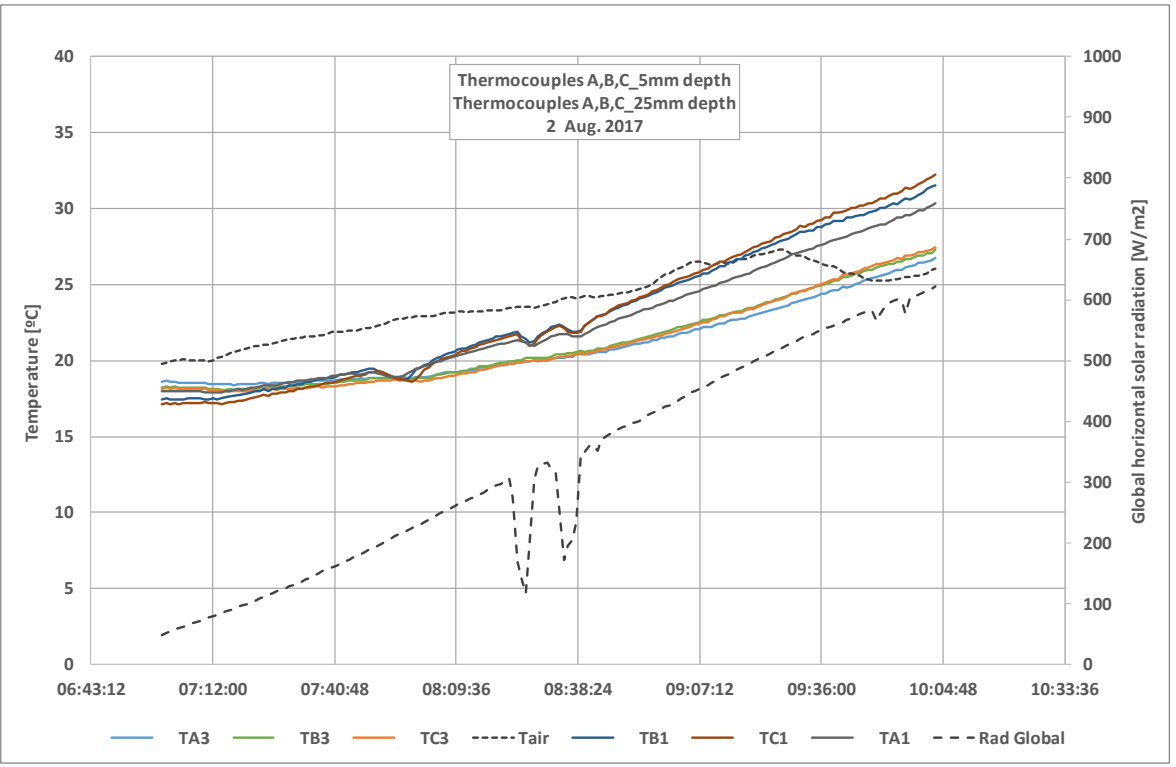

Figure 3: Temperature registered by thermocouples, laid at $5 \mathrm{~mm}$ and $25 \mathrm{~mm}$ depth, on a dark Rc mortar sample, without PCM.

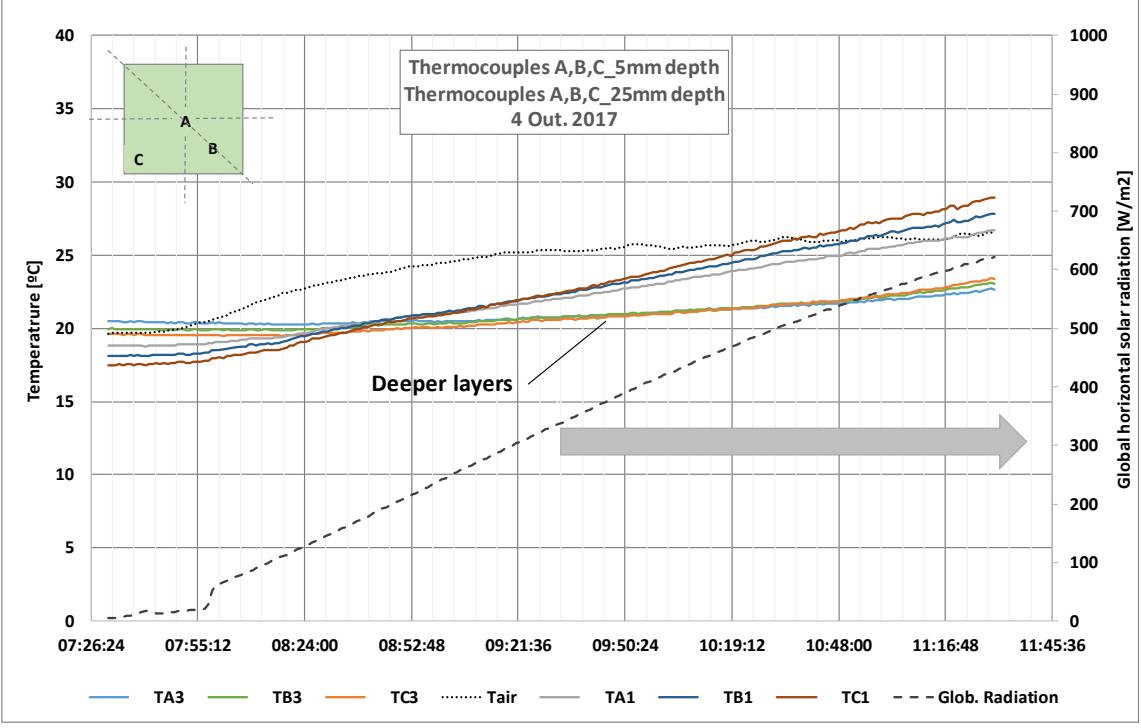

Figure 4: Temperature registered by thermocouples, laid at $5 \mathrm{~mm}$ and $25 \mathrm{~mm}$ depth, on a green coloured Rc mortar sample, with PCM. 
Despite these initial conclusions, a less pronounced gradient was calculated in the temperature region where the phase change, of the PCM sample, must take place, i.e. between $22^{\circ} \mathrm{C}$ and $26-27^{\circ} \mathrm{C}$. This cannot yet be compared to numerical calculations, since the thermophysical properties of the mortar with PCM are still been determined. So, apparently the PCM itself is not enough to ensure the water temperature at desirable values, so it was decided to look up for a different solution.

\subsection{Solar collectors combined with PCM}

In order to take advantage of the sunniest days and excellent Algarve's climate, the new system includes a "temperature-buffer", where solar radiation from sunny days can be stored, either from the solar collectors or from the swimming pool water. This is especially important after a sequence of days with higher heat losses (cloudy days), even during the summer season.

Since the heat accumulator is charged, and at a higher temperature than the water swimming pool, what can happen mainly in cloudy days, the heat will be transferred to the water.

The PCM mortar will be in the centre of the solution, but now being the body of a heat exchanger (HE) with the pool water, which passes by a hydraulic circuit inside the PCM. With this solution one searches a compromise between the number (surface area) of solar collectors and the PCM accumulation volume, at the same time optimizing the energy supplied by the auxiliary circulation pumps (Fig. 5). This must work only when there is one possibility to carry on energy, wherever it comes from, or it goes to.

Among the several possibilities to build the PCM heat exchanger, the elected solution considers the pipes of the hydraulic system disposed along the swimming pools sides, leaning against the walls. This provides more space for all the swimming pool auxiliary equipment, and, at the same time, it spares one side thermal isolation. This solution is still being tested and the results are not yet available.

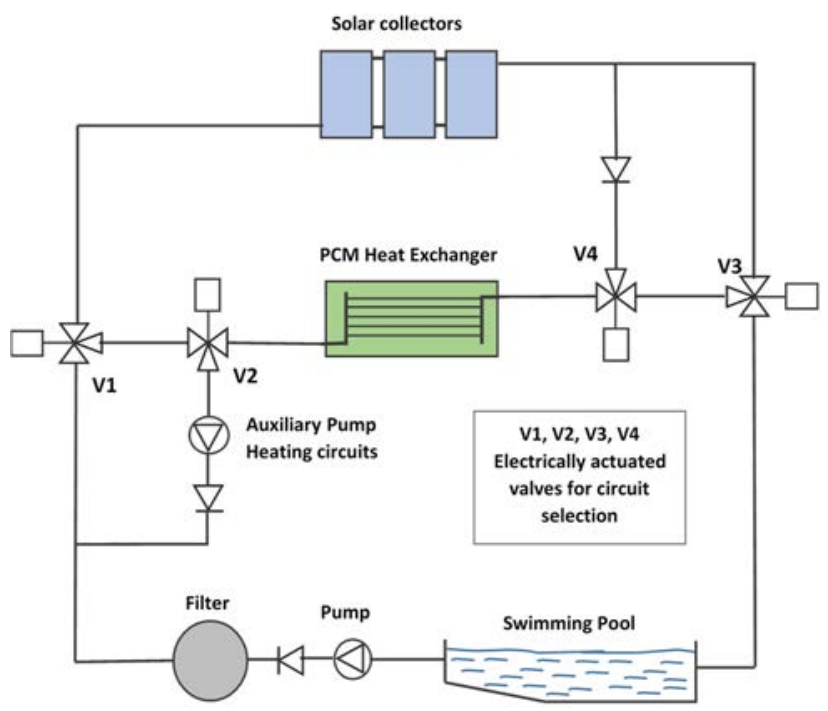

Figure 5: Schematic diagram of the hydraulic circuit combining the solar collectors, PCM heat exchanger and swimming pool. 


\section{APPLICATION OF SPRAYED CONCRETE WITH RECYCLED AGGREGATES}

Sprayed concrete is a concrete pneumatically projected at high velocity from a nozzle to produce a dense homogenous mass. It often incorporates a combination of admixtures and additions or fibres. The material, which has zero or very low slump, is compacted by the force of the jet impacting on the surface and can support itself without sagging whether on a vertical, sloping or, within certain limits, an overhead surface. Rebound, material which bounces off the surface, is inevitable when concrete is projected at a relatively hard surface at high speed. Sprayed concrete is a flexible, economic and rapid construction method, but it requires a high degree of mechanization and specialized workers. It offers an exceptional number of sustainability advantages [21], for both new construction and repair/rehabilitation operations, namely: a) crane and other lifting equipment saving or elimination; b) labour savings of at least $50 \%$ in repair applications; c) new construction speed savings of $33 \%$ to $50 \%$; d) adaptability to repair surfaces that are not cost-effective with other processes; e) better bonding to the substrate enhances durability; f) complex shapes require very little, if any, formwork; g) formwork does not have to be designed for internal purposes; h) material savings through elimination/reduction of formwork; i) speed of repair reduces or eliminates downtime.

There are basically two distinct forms of shotcrete, depending of the amount of water present on the process, when the concrete is introduced into the spaying machine. For the case in which all the water is present, the technique is named wet-mix shotcrete; on the other hand, when the materials are introduced into the spraying machine in the bone-dry state or containing only a part of the mixing water, the technique is named dry-mix shotcrete.

In this project, the last method was chosen, since the Cristalpools company uses it very often in their daily construction works and as already acquired huge practical experience in its application. The materials used on the swimming pool concrete are: Portland cement 32.5, river sand and small gravel. In addition, with the intention of increasing the sustainability of the solutions, fly ashes, blast furnace slag, artificial sand and recycled aggregates (CeRA and CoRA) were incorporated. Table 3 shows the proportions of the various materials used on four different concrete mixtures.

The different concrete compositions were projected on a vertical wall. Afterwards specimens were collected from it, in order to submit them to axial compressive test (EN 12390-3), as well as to water absorption tests (RILEM TC 116-PCD). Table 4 shows the results obtained after 28 days.

It is noted that the introduction of recycled aggregates, and other types of binder, substantially reduced the properties of the concrete. Further compositions will be tested in the future, including the introduction of coarse recycled aggregates.

Table 3: Proportions of the materials use on four different concrete mixtures.

\begin{tabular}{c|c|c|c|c}
\hline \multicolumn{5}{c}{ Volume proportions } \\
\hline Materials & SC Ref 1 & SC CeRA & SC CoRA & SC Ref 2 \\
\hline Portland cement 32.5 & - & 1 & 1 & 1 \\
\hline Fly ashes & ---- & 0.5 & 0.5 & ---- \\
\hline Blast furnace slag & ---- & 0.5 & 0.5 & ---- \\
\hline River sand & 1.5 & ---- & ---- & --- \\
\hline Artificial sand & ---- & ---- & ---- & 1.5 \\
\hline Gravel (<8mm) & 0.5 & ---- & --- & 0.5 \\
\hline CeRA recycled aggregates & ---- & 4 & ---- & --- \\
\hline CoRA recycled aggregates & ---- & ---- & 4 & --- \\
\hline
\end{tabular}


Table 4: Axial compressive and water absorption test results on the four concrete mixtures.

\begin{tabular}{c|c|c|c|c}
\hline \multicolumn{5}{c}{ Results after 28 days } \\
\hline Materials & SC Ref 1 & SC CeRA & SC CoRA & SC Ref 2 \\
\hline $\begin{array}{c}\text { Compressive resistance } \\
\mathrm{MPa}\end{array}$ & 44.8 & 22.3 & 23.6 & 31.6 \\
\hline $\begin{array}{c}\text { Water absorption } \\
\mathrm{g} / \mathrm{m}^{2} \text { after 24 hours }\end{array}$ & 18.0 & 26.6 & 26.8 & 19.4 \\
\hline
\end{tabular}

\section{CONCLUSIONS}

This research work, carried out by a multidisciplinary team, presented measures that have environmental and social advantages and economic benefits. Although the project is still at an intermediate stage, where developments continue to be implemented and tested, the preliminary results point out to a substantial improvement in many aspects in order to turn swimming pools more sustainable in the future.

\section{ACKNOWLEDGEMENTS}

Financial support from the European Regional Development Fund, Programa Operacional Competitividade e Internacionalização, grant SPOOLs - POCI-01-0247-FEDER-01771, is gratefully acknowledged.

\section{REFERENCES}

[1] Instituto Nacional de Estatística, I.P., Revista de Estudos Demográficos, Lisboa, pp. 65-94, 2017.

[2] Região de Turismo do Algarve, Plano de marketing estratégico para o turismo do algarve 2015-2018, Faro, pp. 160-291, 2014.

[3] World Tourism Organization, Indicators of Sustainable Development for Tourism Destinations: A Guidebook, Madrid, pp. 171-196, 2004. ISBN: 92-844-0726-5.

[4] OBSERVE - OBservatório da SustEntabilidade da Região do AlgarVE para o turismo. Online. www.ualg.pt/pt/content/observatorio-da-sustentabilidade-para-turismo.

Accessed on: 3 Mar. 2018.

[5] Gössling, S. et al., Tourism and water use: Supply, demand, and security. An international review. Tourism Management, 33(1), pp. 1-15, 2012. DOI: 10.1016/j.tourman.2011.03.015.

[6] Tyler, G., Harrison, T., Hulverson, R. \& Hristovski, K., Estimating water, energy, and carbon footprints of residential swimming polls. Water Reclamation and Sustainability, pp. 343-359, 2014. DOI: 10.1016/b978-0-12-411645-0.00014-6.

[7] Davenport, J. \& Davenport, J.L., The impact of tourism and personal leisure transport on coastal environments: A review. Estuarine, Coastal and Shelf Science, 67, pp. 280292, 2006. DOI: 10.1016/j.ecss.2005.11.026.

[8] Maia, R. \& Silva, C., DSS application at a river basin scale, taking into account water resources exploitation risks and associated costs: The Algarve Region. Desalination, 237, pp. 81-91, 2009. DOI: 10.1016/j.desal.2007.12.024.

[9] Karatayev, M., Kapsalyamova, Z., Spankulova, L., Skakova, A., Movkebayeva, G. \& Kongyrbay, A., Priorities and challenges for a sustainable management of water resources in Kazakhstan. Sustainability of Water Quality and Ecology, 9-10, pp. 115135, 2017. DOI: 10.1016/j.swaqe.2017.09.002.

[10] Bastos, M.R., Dias, J.A., Dias, A.C., Pereira, S.D., De Oliveira, N.V. \& Rodrigues, M.A., Sustainable coastal zones. A matter of sense and sensibility: Comparative 
analysis between Aveiro Lagoon (Portugal) and Sepetiba Bay (Brazil). Management of Environmental Quality: An International Journal, 23(4), pp. 383-399, 2012.

[11] Veldhoven, K. et al., Effects of exposure to water disinfection by-products in a swimming pool: A metabolome-wide association study. Environment International, 111, pp. 60-70, 2018.

[12] Skibinski, B., Gotze, C., Worch, E. \& Uhl, W., Pore diffusion limits removal of monochloramine in treatment of swimming pool water using granular activated carbon. Water Research, 132, pp. 270-281, 2018.

[13] Yang, L., She, Q., Wan, M.P., Wang, R., Chang, V. \& Tang, C., Removal of haloacetic acids from swimming pool water by reverse osmosis and nanofiltration. Water Research, 116, pp. 116-125, 2017.

[14] Szala, M., Beer-Lechb, K. \& Walczak, M., A study on the corrosion of stainless steel floor drains in an indoor swimming pool. Engineering Failure Analysis, 77, pp. 3138, 2017.

[15] Felixberger Josef, K., Damage When Tiling Swimming Pools and its Avoidance, Qualicer 2008, 10-13 Feb., Castellón Spain, 2008.

[16] Eaton, A.D., Clesceri, L.S., Rice, E. \& Greenberg A., Standard Methods for the Examination of Water and Wastewater, 21st ed., American Public Health Association, American Water Works Association and Water Environmental Federation: Washington, 2005.

[17] Neville, A. M., History of high-alumina cement. Part 1: Problems and the stone report. Proceedings of the Institution of Civil Engineers - Engineering History and Heritage, 162(2), pp. 81-91, 2009. DOI: 10.1680/ehh.2009.162.2.81.

[18] Eckert, M. \& Oliveira, M., Mitigation of the negative effects of recycled aggregate water absorption in concrete technology. Construction and Building Materials, 133, pp. 416-424, 2017.

[19] Zalba, B., Marin, J.M., Cabeza L.F. \& Mehling, H., Review on thermal energy storage with phase change: Materials, heat transfer analysis and applications. Applied Thermal Engineering, 23, pp. 251-283, 2003.

[20] Soares, N., Costa, J.J., Gaspar, A.R. \& Santos, P., Review of passive PCM latent heat thermal energy storage systems towards buildings' energy efficiency. Energy and Buildings, 59, pp. 82-103, 2013.

[21] Online sources: The Sustainable Concrete Guide-Applications; U.S. Green Concrete Council, American Concrete Institute. Online. www.concrete.org. Accessed on: 23 Jun. 2017. 